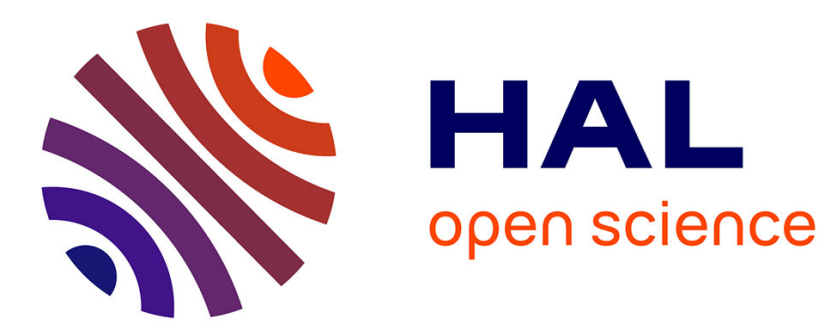

\title{
Hygrothermal modeling and MPC-based control for energy and comfort management in buildings
}

\author{
Farah Gabsi, Frédéric Hamelin, Nathalie Sauer
}

\section{To cite this version:}

Farah Gabsi, Frédéric Hamelin, Nathalie Sauer. Hygrothermal modeling and MPC-based control for energy and comfort management in buildings. International Conference on Smart Grid and Clean Energy Technologies, ICSGCE 2018, May 2018, Kajang, Malaysia. hal-01825455

\section{HAL Id: hal-01825455 \\ https://hal.science/hal-01825455}

Submitted on 28 Jun 2018

HAL is a multi-disciplinary open access archive for the deposit and dissemination of scientific research documents, whether they are published or not. The documents may come from teaching and research institutions in France or abroad, or from public or private research centers.
L'archive ouverte pluridisciplinaire HAL, est destinée au dépôt et à la diffusion de documents scientifiques de niveau recherche, publiés ou non, émanant des établissements d'enseignement et de recherche français ou étrangers, des laboratoires publics ou privés. 


\section{Hygrothermal Modeling and MPC-based Control for Energy and Comfort Management in Buildings}

\author{
Farah Gabsi \\ Université de Lorraine \\ CNRS, CRAN, F-54000 Nancy, France \\ LGIPM, F-57000 Metz, France \\ Farah.Gabsi@univ-lorraine.fr
}

\author{
Frédéric Hamelin \\ Université de Lorraine \\ CNRS, CRAN, F-54000 Nancy, France \\ Frederic.Hamelin@univ-lorraine.fr
}

\author{
Nathalie Sauer \\ Université de Lorraine \\ LGIPM, F-57000 Metz, France \\ Nathalie.Sauer@univ-lorraine.fr
}

\begin{abstract}
This article treats the problem of modeling and controlling a multi-zone office building to ensure its hygrothermal comfort through optimal and cost-effective management. An analysis of the hygrothermal behavior is carried out, which leads to a set of descriptor state-space models. Based on this modeling, an iterative optimization algorithm is proposed to solve the optimization problem associated to the model predictive control (MPC) design. By means of an original cost function based on peak/no peak energy consumption, significant energy savings can be envisaged in practice.
\end{abstract}

Index Terms-buildings, hygrothermal modeling, modelpredictive control, energy efficiency, thermal comfort.

\section{INTRODUCTION}

Since the entry into force of the Kyoto Protocol on 2005 , the building sector has been encouraged to reduce its consumption of energy and materials. These efforts have resulted in thermal regulations, environmental quality or energy performance labels. More recently, in France, the Grenelle Environment has confirmed the potential of the building sector in terms of energy saving.

The envelope of a building is the interface between the inner ambience and the external environment. It is the seat of transfers of heat, humidity, and air, which determine the internal climate of the building. Most often, it must be supplemented by a regulation system (heating, humidification, refreshment, air renewal...). The introduction of the Model Predictive Control (MPC) in the sector of building turns out very promising to maintain the comfort of the occupants and to generate energy savings. This type of control is favored because it has the advantage of taking into account the disturbance predictions that greatly influence the interior comfort of buildings (outside temperature, sunshine, occupations,...) while anticipating their effects [1], [2], [3], [4]. Recent studies have highlighted the risks associated with humidity in buildings: deterioration of conditions of comfort or hygiene, decrease of energy performance. However, very little work considers the hygrothermal control of buildings [5].

This work has financial support from the Contrat de Plan Etat-Région (CPER) Lorraine 2015-2020, project "Matériaux, Energie, Procédés".
In this paper, a complete methodology of modeling/ controlling a multi-zone office building is proposed, the objective is to improve the hygrothermal comfort of the occupants while minimizing the energy consumed. The modeling step, which is essential for the design of a MPC, is based on a physical description of the building [6]. Knowing that each control action will be associated with a different descriptor state-space model of the system, the predictive control strategy will be of the hybrid type. In view of the control objectives, the optimization criterion associated to the MPC will integrate the energy cost of each actuator in euros, and will be solved by an iterative algorithm in order to avoid a risk of combinatory explosion. The first part of this work is focused on the hygrothermal modeling of a set of zones. Then a MPCbased control strategy is proposed to ensure the hygrothermal comfort of a set of zones with a minimal energy consumption.

\section{Hygrothermal COMFORT}

The notion of thermal comfort in a building is related not only to the quality of the interior atmospheres, but also to the amount of energy to be supplied by the equipments. In ISO 7730 [7], a method was presented to predict the thermal sensation and the degree of discomfort (thermal dissatisfaction) of people exposed to moderate thermal environments and to specify thermal conditions acceptable for comfort. Considering a volume of air (i) (called afterwards zone (i)) bounded by $n$ walls, this standard defines a felt comfort temperature, also known as "operative temperature" or "dry resulting temperature" by:

$$
T_{o(1)} \approx \frac{T_{m r(1)}+T_{(1)}}{2}
$$

where $T_{\Phi}$ is the ambient temperature of the air, $T_{k \Phi}(1 \leqslant k \leqslant$ $n$ ) are the temperatures of the $n$ walls with surfaces equal to $S_{k(1)}$ and $T_{m r(1)}$ is the mean radiant temperature [8] defined by:

$$
T_{m r(1)}=\frac{\sum_{k} S_{k(1)} \times T_{k \oplus}}{\sum_{k} S_{k(1)}}
$$

A first criterion to consider for the design of the control law is to ensure that operational temperature $T_{o(1)}$ (1) belongs to a comfort temperature range defined by $T_{\text {comf }} \pm 2 \mathrm{~K}$ where 
$T_{\text {comf }}(k)$ is a comfort temperature [9] related to the outside air temperature. Nevertheless, a source of thermal discomfort remains if the difference between the ambient temperature $T_{\odot}$ and the surface temperature $T_{k_{\odot}}$ of each wall is too big. So, the MPC objectives have to include $\left|T_{\oplus}-T_{k_{\odot}}\right|<8 \mathrm{~K}$ for glazed surfaces and $5 \mathrm{~K}$ for opaque walls.

The last appellation of thermal comfort used by the HQE (High Quality Environmental) standard is the "hygrothermal comfort", because the latter depends not only on the temperature, but also on the air humidity [10]. More precisely, the hygrothermal comfort depends on the air and surface temperatures, humidity and air movements. To measure the moisture content of the air, one defines the relative humidity of the air $\phi_{(1)}$ according to the relation:

$$
\phi_{(1}(\%)=100 \frac{P_{v(1)}}{P_{v s(1)}}=100 \frac{\rho_{v(1)}}{\rho_{v s(1)}}
$$

where $\rho_{v(1)}$ and $\rho_{v s(1)}$ are the densities of water vapor in zone (i) associated respectively with vapor pressure $P_{v(1)}$ and saturation vapor pressure $P_{v s(1)}$ that is such that [8]:

$$
P_{v s(1)}=610,78 \times \exp \left(\frac{17.269\left(T_{(1)}-273.15\right)}{T_{(1)}-35.85}\right)
$$

According to the air quality standards recommended for France, the MPC will have to ensure a humidity rate $\phi_{\oplus}(\%)$ of between 40 and $60 \%$.

\section{HygRothermal MODELING}

In this paragraph is presented the set of balance equations governing the dynamic behaviour of temperature and relative

TABLE I:

\begin{tabular}{|c|c|c|}
\hline Par. & Description & SI units \\
\hline$C_{m k}$ & Specific moisture capacity of material $\left(\Sigma_{k}\right)$ & $\mathrm{kg} /(\mathrm{kg} \cdot \mathrm{Pa})$ \\
\hline$C_{p_{d a}}$ & Specific heat capacity of dry air $(=1006)$ & $\mathrm{J} /(\mathrm{kg} \cdot \mathrm{K})$ \\
\hline$C_{p k}$ & Specific heat capacity of material $\left(\Sigma_{k}\right)$ & $\mathrm{J} /(\mathrm{kg} \cdot \mathrm{K})$ \\
\hline$C_{p_{v}}$ & $\begin{array}{l}\text { Specific heat capacity of water vapor } \\
(=1860)\end{array}$ & $\mathrm{J} /(\mathrm{kg} \cdot \mathrm{K})$ \\
\hline$h_{c}$ & $\begin{array}{l}\text { Heat transfer coefficient }(\approx 8.3 \text { (interior) } \\
\text { and } \approx 34 \text { (exterior; normal conditions) } \\
[11])\end{array}$ & $\mathrm{W} /\left(\mathrm{m}^{2} \cdot \mathrm{K}\right)$ \\
\hline$h_{m}$ & $\begin{array}{l}\text { Water vapor transfer coefficient } \\
\left(\approx 7 e^{-9} \times h_{c}\right)\end{array}$ & $\mathrm{kg} /\left(\mathrm{m}^{2} \mathrm{~s} \cdot \mathrm{Pa}\right)$ \\
\hline$h_{v}$ & $\begin{array}{l}\text { Latent heat of vaporization of water } \\
\left(=2.5 e^{6}\right)\end{array}$ & $\mathrm{J} / \mathrm{kg}$ \\
\hline$n_{a}$ & Number of moles of air per $m^{3}(\approx 41)$ & $\mathrm{mol} / \mathrm{m}^{3}$ \\
\hline$P_{d a(1)}$ & Dry air pressure of zone (i) & $\mathrm{Pa}$ \\
\hline$R_{d a}$ & Gas constant for dry air $=287.1$ & $\mathrm{~J} /(\mathrm{kg} \cdot \mathrm{K})$ \\
\hline$R_{v}$ & Gas constant for water vapor $=461.5$ & $\mathrm{~J} /(\mathrm{kg} \cdot \mathrm{K})$ \\
\hline $\begin{array}{l}S_{k(1)} \\
V_{\oplus}\end{array}$ & $\begin{array}{l}\text { Area of surface }\left(\Sigma_{k}\right) \text { in contact with zone (i) } \\
\text { Volume of zone }(\mathrm{i})\end{array}$ & $\mathrm{m}^{2}$ \\
\hline$V_{k}$ & Volume of material $\left(\Sigma_{k}\right)$ & $\mathrm{m}^{3}$ \\
\hline$\delta_{p k}$ & $\begin{array}{l}\text { Vapor permeability of material }\left(\Sigma_{k}\right) \\
\quad\left(\frac{e_{k}}{\delta_{p k}}=R_{k} \text { is the moisture resistance) }\right.\end{array}$ & $\mathrm{kg} /(\mathrm{m} \cdot \mathrm{s} \cdot \mathrm{Pa})$ \\
\hline$\lambda_{k}$ & $\begin{array}{l}\text { Thermal conductivity of material }\left(\Sigma_{k}\right) \\
\left(\frac{e_{k}}{\lambda_{k}}=R_{k} \text { is the thermal resistance }\right)\end{array}$ & $\mathrm{W} /(\mathrm{m} \cdot \mathrm{K})$ \\
\hline$\rho_{d a(1)}$ & Density of dry air in zone (i) & $\mathrm{kg} / \mathrm{m}^{3}$ \\
\hline
\end{tabular}

NOMENCLATURE humidity within a zone (i). The approximations made are justified by taking as an example the city of Nancy (France, $\approx 230 \mathrm{~m}$ altitude). The definition of the different parameters is specified either in the text or in the Table I.

\section{A. Energy and Moisture Balances}

The energy balance equation in zone (i) delimited by $n$ walls matches the sum of all incoming or outgoing heat fluxes to the temporal variation of enthalpy $H_{\oplus}(t)$ of moist air:

$$
\begin{aligned}
& \dot{H}_{\oplus}(t)=\left(\rho_{d a \oplus}(t) C_{p_{d a}}+\rho_{v \circledast}(t) C_{p_{v}}\right) V_{\oplus} \dot{T}_{\oplus}(t) \\
& =C_{p_{d a} \rho_{d a \oplus}}(t)\left(1+\frac{C_{p_{v}} \rho_{v(\mathbb{}}(t)}{C_{p_{d a}} \rho_{d a(1)}(t)}\right) V_{\oplus} \dot{T}_{\oplus}(t) \\
& =C_{p_{d a}} \frac{P_{d a \oplus}(t)}{R_{d a} T_{\oplus}(t)}\left(1+1.15 \frac{P_{v(1)}(t)}{P_{d a(1}(t)}\right) V_{\oplus} \dot{T}_{\oplus}(t) \\
& =\sum_{j} q_{j \oplus}(t)
\end{aligned}
$$

knowing that $\rho_{d a \oplus}(t)=\frac{P_{d a \oplus}(t)}{R_{d a} T_{\oplus}(t)}$ and $\rho_{v \oplus}(t)=\frac{P_{v(1}(t)}{R_{v} T_{\oplus}(t)}$.

This nonlinear differential equation can be approximated by a linear differential equation by considering local weather conditions. Indeed, according to (4) and inequality $288 \mathrm{~K}<$ $T_{\oplus 1}(t)<308 \mathrm{~K}$, it follows knowing that generally in France $980 \mathrm{hPa}<P_{0 \oplus}(t)<1040 \mathrm{hPa}:$

$$
\begin{aligned}
1.11-1.25 e^{-4} z & <\frac{P_{d a \oplus}(t)}{R_{d a} T_{\oplus}(t)}\left(1+1.15 \frac{P_{v \Phi}(t)}{P_{d a \oplus}(t)}\right) \\
& <1.26-1.42 e^{-4} z
\end{aligned}
$$

taking into account atmospheric pressure variations $P_{z \oplus}(t)$ as a function of altitude ( $z$ in metres):

$$
P_{z \oplus}(t) \approx P_{0 \oplus}(t)\left(1-\frac{0.0065 z}{288.15}\right)^{5.255}
$$

Therefore, for the city of Nancy, (5) can be approached by the following linear differential equation with a maximum error of $\pm 9 \%$ on the estimation of the term weighting $\dot{T}_{\oplus}(t)$ :

$$
1.15 \times C_{p_{d a}} V_{\oplus} \dot{T}_{\oplus}(t)=\sum_{j} q_{j \oplus}(t)
$$

As for the moisture balance equation in zone (i), it is given by:

$$
V_{\text {(1) }} \dot{\rho}_{v(1)}(t)=\sum_{j} g_{j(1)}(t)
$$

If the surfaces (walls/windows/doors/ceiling/floor) surrounding zone (i) are now considered, the energy balance equation associated with each homogeneous and isotropic material $\left(\Sigma_{k}\right)(1 \leqslant k \leqslant n)$ of thickness $e_{k}$ delimited by the two parallel surfaces $\left(\Sigma_{k_{\oplus}}\right)$ and $\left(\Sigma_{k_{\oplus}}\right)$ is given by:

$$
\begin{aligned}
& \rho_{k} C_{p k} V_{k} \dot{T}_{k}(t)=-2 S_{k} \times \sum_{\mathbb{1}=\Phi, \Phi} \frac{\lambda_{k}}{e_{k}}\left(T_{k}(t)-T_{k \Phi}(t)\right) \\
&-\frac{2 S_{k} \sigma h_{v}}{\rho_{k} C_{m k}} \times \sum_{\mathbb{\Phi}=\Phi, \Phi} \frac{\delta_{p k}}{e_{k}}\left(\rho_{v k}(t)-\rho_{v k \Phi}(t)\right)
\end{aligned}
$$


with:

$$
\left\{\begin{array}{l}
\rho_{v k}(t)=\rho_{k} C_{m k} P_{v k}(t) \\
\rho_{v k \oplus}(t)=\rho_{k} C_{m k} P_{v k \oplus}(t)
\end{array}\right.
$$

and where the temperature, the partial vapor pressure and the vapor density characterizing the middle of $\left(\Sigma_{k}\right)$ and each of the two surfaces $\left(\Sigma_{k_{\oplus}}\right)$ and $\left(\Sigma_{k \oplus}\right)$ are given by $\left(T_{k}(t), P_{v k}(t), \rho_{v k}(t)\right), \quad\left(T_{k \oplus}(t), P_{v k \oplus}(t), \rho_{v k \oplus}(t)\right)$ and $\left(T_{k \Phi}(t), P_{v k \Phi}(t), \rho_{v k \Phi}(t)\right)$ respectively.

As for the mass balance equation at $\left(\Sigma_{k}\right)$, it is given by:

$$
V_{k} \dot{\rho}_{v k}(t)=\frac{-2 S_{k}}{\rho_{k} C_{m k}} \times \sum_{\mathbb{\Phi}=\oplus, \Phi} \frac{\delta_{p k}}{e_{k}}\left(\rho_{v k}(t)-\rho_{v k \Phi}(t)\right)
$$

The link between equations (8), (9) and (10), (12) is established by considering the convective heat / moisture flux between air of zone (i) and the $n$ surfaces [12]:

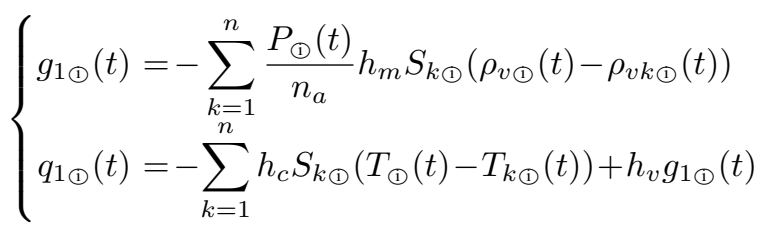

\section{B. Main Mass and Heat Exchanges within a Zone}

1) Heating/cooling systems: Air treatment systems in buildings do not just cool/heat but also treat, filter and humidify indoor air. In this paper, we assume that the temperature $T_{h}$, $T_{c}$ (in K) and the vapor density $\rho_{v, h}, \rho_{v, c}$ of the forced-air (in $\mathrm{kg} / \mathrm{m}^{3}$ ) in heating / cooling mode are known. The focus is on reversible heat pumps (HP). These are thermodynamic devices for transferring heat from a "cold source" to a "hot source", although naturally the heat is diffused from the warmest to the coldest place. Thus, the thermal comfort in a building can be ensured by heat pumps that refresh in summer and heat in winter. Essentially, and without taking into account the transitional aspects, the equations translating this energy flow in zone (i) is in heating/cooling mode:

$$
\left\{\begin{array}{l}
g_{2 \oplus}(t)=-Q_{H P}\left(\rho_{v \oplus}(t)-\rho_{v, h / c}(t)\right) \\
q_{2 \oplus 1}(t)=-1.15 \times Q_{H P} C_{p_{d a}}\left(T_{\oplus}(t)-T_{h / c}\right)
\end{array}\right.
$$

with $Q_{H P}$ the air flow of the HP (in $\left.\mathrm{m}^{3} / \mathrm{s}\right)$.

2) Occupancy and equipments: Table II shows the energy and the water vapour released by one person depending on his activity and the temperature of the area in which he is located. According to (13), $q_{3 \text { (1) }}$, presented within Table II, represents an estimate of the total heat emitted by a person. It includes body heat (related to body temperature $310 \mathrm{~K}$ ) and the latent heat by the production of water vapour in breath and perspiration.

$$
q_{3 \oplus}(t) \approx-\gamma\left(T_{\oplus}(t)-310\right)+h_{v} g_{3 \oplus}(t)
$$

Many other equipments produce heat in a room. Being of a diverse nature and of a different power (lighting, computer
TABLE II:

HEAT/MOISTURE FLUX

\begin{tabular}{c|cc|cc|cc|} 
& \multicolumn{2}{|c|}{$\begin{array}{c}\text { Rest to } \\
\text { light activity }\end{array}$} & \multicolumn{2}{|c|}{$\begin{array}{c}\text { Light to sustai- } \\
\text { ned activity }\end{array}$} & \multicolumn{2}{c|}{$\begin{array}{c}\text { Heavy } \\
\text { physical activity }\end{array}$} \\
\hline$T_{(1)}$ & $g_{3(1)}$ & $q_{3(1)}$ & $g_{3(1)}$ & $q_{3(1)}$ & $g_{3(1}$ & $q_{3(1}$ \\
$(\mathrm{C})$ & $(\mathrm{g} / \mathrm{h})$ & $(\mathrm{W})$ & $(\mathrm{g} / \mathrm{h})$ & $(\mathrm{W})$ & $(\mathrm{g} / \mathrm{h})$ & $(\mathrm{W})$ \\
\hline 18 & 35 & 125 & 95 & 190 & 165 & 270 \\
22 & 40 & 120 & 125 & 190 & 215 & 270 \\
26 & 65 & 115 & 150 & 190 & 250 & 270 \\
\hline
\end{tabular}

equipment, furnace,...), they will not be considered in this work.

3) Solar radiations: The total solar radiation received by a surface, called incident solar irradiation (or even global energy irradiance), is defined as the sum of three components:

- Direct solar radiation. This component cancels if the sun is hidden by clouds or by an obstacle;

- Diffused radiation, corresponding to the radiation received from the celestial vault, without direct radiation. This energy diffused by the atmosphere and directed towards the surface of the Earth, can reach $50 \%$ of the overall radiation received, when the sun is low on the horizon, and $100 \%$ for a fully covered sky;

- Reflected radiation, corresponding to the radiation reflected by the external environment, especially the soil, whose reflection coefficient is called "albedo".

To quantify the global radiation, it is necessary to consider the local latitude $(\Phi)$, the hour angle $(\omega)$ in the local solar time, the solar declination $\left(\delta_{s}\right)$ and the solar azimuth $\left(\phi_{s}\right)$ [13]. The energy related to direct solar radiation is then such that:

$$
\begin{aligned}
q_{4 \oplus}(t)=1260 & S_{w k} \exp \left(\frac{-1}{2.3\left(\alpha_{s}(t)+3\right) \sin \left(\alpha_{s}(t)\right)}\right) \\
& \times \cos (\beta(t))
\end{aligned}
$$

where $S_{w k}$ is the glazed surface of $\left(\Sigma_{k}\right), \alpha_{s}(t)$ is the solar elevation angle defined by:

$$
\begin{aligned}
\alpha_{s}(t)=\arcsin & \left(\sin (\Phi) \sin \left(\delta_{s}(t)\right)\right. \\
& \left.+\cos (\Phi) \cos \left(\delta_{s}(t)\right) \cos (\omega(t))\right)
\end{aligned}
$$

and $\beta(t)$ is the angle of incidence between the suns rays and face of the windows.

$$
\begin{gathered}
\beta(t)=\arccos \left(\cos \left(\alpha_{s}(t)\right) \sin (i) \cos \left(\phi_{s}(t)-o r\right)\right. \\
\left.+\sin \left(\alpha_{s}(t)\right) \cos (i)\right)
\end{gathered}
$$

The determination of $\alpha_{s}(t)$ and $\beta(t)$ requires the calculation of the solar angle $\omega(t)$ (rad):

$$
\omega(t)=\frac{\pi}{12}(12-h(t))
$$

of the solar azimuth angle $\phi_{s}(t)$ :

$$
\phi_{s}(t)=\arcsin \left(\frac{\cos \left(\delta_{s}(t)\right) \sin (\omega(t))}{\cos \left(\alpha_{s}(t)\right)}\right)
$$


and of the current sun declination $\delta_{s}(t)$, which is the angle between the sun direction and the plane of the Equator :

$$
\begin{aligned}
\delta_{s}(t)=\frac{0.18}{\pi}( & 6.92-400 \cos (\Gamma(t))-6.8 \cos (2 \Gamma(t)) \\
& -2.7 \cos (3 \Gamma(t))+70 \sin (\Gamma(t)) \\
& +0.9 \sin (2 \Gamma(t))+1.5 \sin (3 \Gamma(t)))
\end{aligned}
$$

where:

- $h(t)$ is the true solar time;

- $\Gamma(t)=2 \pi\left(d_{n}(t)-1\right) / 365$ corresponds to the day angle calculated from day number $d_{n}(t) \in \mathbb{R}$ taking into account hours and minutes;

- latitude $\Phi$ is determined according to the position of the building ( $\Phi=0.85 \mathrm{rad}$ for Nancy, France);

- the orientation of the windows is indicated by variable or;

- $i$ corresponds to the inclination of the windows according to the horizontal $(i=\pi / 2 \mathrm{rad})$.

As for the energy associated to the diffused radiation energy, it is calculated by the relationship:

$$
\begin{aligned}
q_{5 \oplus 1}(t)=S_{w k} & \left(62.5 \times(1+\cos (i)) \sin \left(\alpha_{s}(t)^{0.4}\right)\right. \\
+ & \left.108 \times(1-\cos (i)) \sin \left(\alpha_{s}(t)^{1.22}\right)\right)
\end{aligned}
$$

with an albedo approximatively equal to $20 \%$.

Remark 1: When the sun's rays reach an opaque wall, part of the solar radiation is absorbed by the various materials that make up this wall. There is no radiation transmitted since the wall is opaque. The inertia of the wall determines the response time. In order to reflect the solar energy transmitted by these opaque walls and to consider the inertia of the latter, it is possible to use the concept of equivalent outdoor temperature, which integrates the solar radiation and the characteristics of the opaque walls (absorption capacity and inertia).

\section{State-Space Modeling}

According to the previous developments, the dynamical hygrothermal behavior of zone (i) bounded by $n$ walls $\left(\Sigma_{k}\right)$ can be represented by a set of $N_{s}$ descriptor state-space models, each of them being associated with a particular control scenario $(\mathrm{HP}(\mathrm{ON}-\mathrm{OFF}), \ldots)$ :

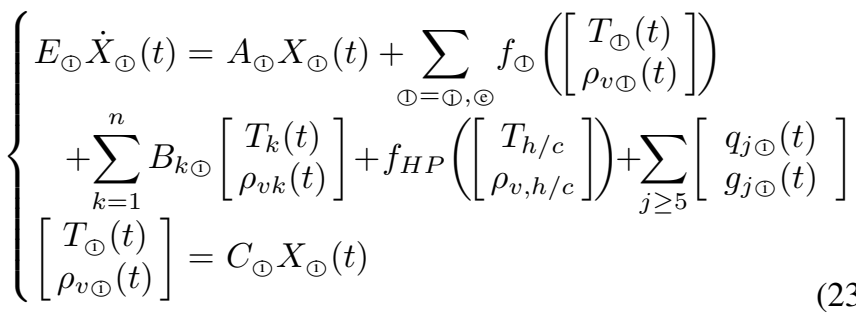

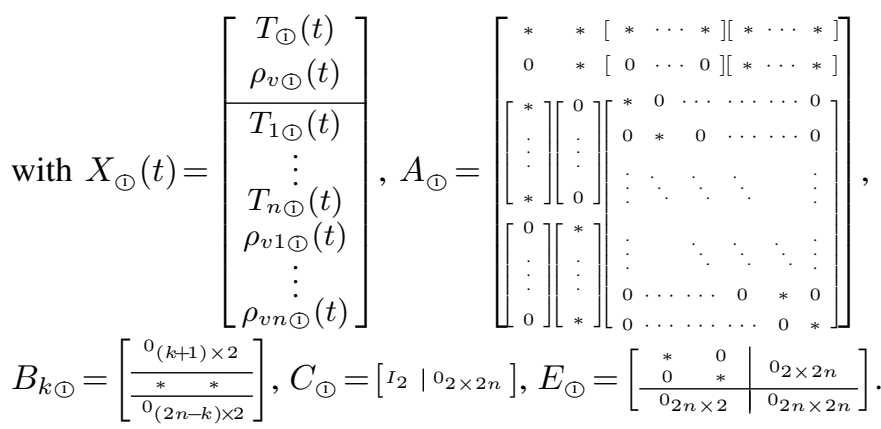

The connection with the other zones (i) of the building is carried out by the state-space model of all the walls $\left(\Sigma_{k}\right)$ surrounding zone (i):

$$
\dot{X}_{k}(t)=A_{k} X_{k}(t)+B_{k}\left[\begin{array}{c}
T_{k \oplus}(t) \\
T_{k_{\oplus}}(t) \\
\rho_{v k_{\oplus}}(t) \\
\rho_{v k \Phi}(t)
\end{array}\right]
$$

with $X_{k}(t)=\left[\begin{array}{c}T_{k}(t) \\ \rho_{v k}(t)\end{array}\right], A_{k}=\left[\begin{array}{cc}* & * \\ 0 & *\end{array}\right], B_{k}=\left[\begin{array}{cccc}* & & * & * \\ 0 & 0 & * & *\end{array}\right]$.

In the particular case where wall $\left(\Sigma_{k}\right)$ is in contact with the outside air $((\mathrm{i})=$ (e) $)$ characterized by a temperature $T_{\odot}(t)$ and a density of water equal to $\rho_{v \odot}(t),(24)$ becomes:

$$
\dot{X}_{k}(t)=A_{k} X_{k}(t)+B_{k}\left[\begin{array}{c}
T_{k \oplus}(t) \\
T_{\odot}(t) \\
\rho_{v k \oplus}(t) \\
\rho_{v \odot}(t)
\end{array}\right]
$$

knowing, according to equations (8), (9), (10), (12) and (13), that $T_{k \odot}(t)=a_{k} T_{k}(t)+b_{k} T_{\odot}(t)$ and $\rho_{v k \odot}(t)=c_{k} \rho_{v k}(t)+d_{k} \rho_{v \odot}(t)$ (coefficients $a_{k}, b_{k}, c_{k}$ and $d_{k}$ being related to $h_{c}, h_{m}, \lambda_{k}$ and $\delta_{p k}$ ).

\section{Model Predictive Control}

The principle of the predictive control [2] is to optimize a cost function allowing to describe the aim of control over a finite time horizon. At any moment, an optimal control sequence is calculated to minimize the cost function on a prediction horizon. Only the first element is applied to the system.

\section{A. Cost Function and Constraints}

Since the objective is to ensure the thermal comfort with a minimum of energy consumption, the cost function must reflect these performances in a mathematical formulation. In the light of sections II and III, the cost function is chosen such that:

$$
\begin{array}{r}
J=\min _{i_{1} \ldots, i_{N}} \sum_{j=1}^{N_{p}} \sum_{\oplus}\left(\alpha_{\Phi, j}\left|T_{o \Phi, i_{j}}(k+j)-T_{\text {comf }}(k+j)\right|^{2}\right. \\
\left.+\beta_{\Phi, j}\left|\phi_{\Phi, i_{j}}(k+j)-50\right|^{2}+€_{i_{j}}(k+j)\right)
\end{array}
$$

with :

- $N_{p}$ : the prediction horizon; 
- $T_{o ®, i_{j}}(k+j):$ the predicted operative temperature $T_{o \oplus}$ (1) in zone (1) at time $k+j$ according to the sequence of control scenario $i_{1}, \ldots, i_{j}$;

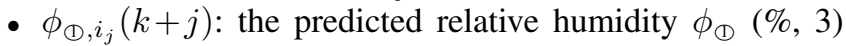
in zone (1) at time $k+j$ according to the sequence of control scenario $i_{1}, \ldots, i_{j}$. It is determined by means of the prediction of $\rho_{v \Phi}(k+j)$, equations (3-4) and with relation $\rho_{v s \Phi}(k+j)=\frac{P_{v s \Phi}(k+j)}{R_{v} T_{\Phi}(k+j)}$;

- $T_{\text {comf }}(k+j)$ : the comfort temperature at time $k+j$;

- $€_{i_{j}}(k+j)$ : the energy cost (in $€$ ) of the control scenario $i_{j}$. It depends on the electricity pricing $C_{€}(k+j)$ (in $€ / \mathrm{kWh}$ ), which varies significantly between off-peak and peak hours. Indeed, national electricity consumption varies by time of day depending on the activities of businesses and individuals. The means of production required to respond instantly to this demand are activated according to a "merit order" logic: the higher the power consumption, the more electricity is expensive to produce.

under the constraints:

- of $N_{s}$ hygrothermal models (23-25). At each step of prediction $k+j$, the model to be adopted depends on the control scenario $i_{j}$ selected;

- of comfort (according to section II):

$$
\left\{\begin{array}{l}
T_{\text {comf }}(k+j)-2 \leq T_{o \oplus, i_{j}}(k+j) \leq T_{\text {comf }}(k+j)+2 \\
\left.\left|T_{\Phi, i_{j}}(k+j)-T_{k \oplus, i_{j}}(k+j)\right|<5 \text { (or } 8\right) \mathrm{K} \\
40 \%<\phi_{\oplus, i_{j}}(k+j)<60 \% \\
\rho_{v k \Phi, i_{j}}(k+j)<\rho_{v s \Phi} \\
\rho_{v k, i_{j}}(k+j)<\rho_{v s k}
\end{array}\right.
$$

These constraints can be easily integrated in the optimization problem (26) because all variables $T_{\mathbb{1}}$, $T_{k \oplus}, \rho_{v k \Phi}, \rho_{v \Phi}$ and $\rho_{v k}$ are components of state vectors $X_{\odot}$ and $X_{k}(23-25)$.

Remark 2: In the context of minimizing the energy consumption, it could be interesting to specify that the hygrothermal constraints of zone (1) are not the same in the absence or in the presence of people. This notion can be reflected using time-varying values for weights $\alpha_{\oplus, j}$ and $\beta_{\oplus, j}$ (for example by taking $\alpha_{\mathbb{D}, j}=\beta_{\mathbb{D}, j}=0$ for an unoccupied zone at time $k+j$ ).

Remark 3: The disturbance inputs $T_{\odot}(k+j), \rho_{v \odot}(k+j)$, $q_{4 \oplus}(k+j)$ and $q_{5 \oplus}(k+j)(16-22)$ are estimated through short-term weather forecasts. $q_{4 \oplus}(k+j)$ and $q_{5 \infty}(k+j)$ require a basic calculation according to the orientation of the windows and predicted solar radiation. $q_{3 \oplus}(k+j)$ and $g_{3 \text { D }}(k+j)$ (section III-B2) can be predicted based on the occupancy planning in zone (1).

\section{B. Iterative Approach to Solving Optimization Problem}

The minimization of criterion $J$ (26) for important values of $N_{p}$ and/or $N_{s}$ quickly becomes impossible using Matlab routines due to the combinatorial explosion in computation time. In practical terms, $N_{p}$ and/or $N_{s}$ can not exceed a few units. Yet it can be very interesting to consider a large value for prediction horizon $N_{p}$. Indeed, an optimal control scenario on a low prediction horizon may become inappropriate on a larger horizon. This happens especially when the heating and/or cooling capabilities of the building are modest or when weights $\alpha_{\Phi, j}$ and $\beta_{\oplus, j}$ are time-dependent (See Remark 2). In order to consider larger value for the prediction horizon $N_{p}$, we have developed an iterative approach [1], whose purpose is to estimate the optimal control scenario, solution of (26), with a controlled computational load. The idea consists in conserving at time of prediction $k+j$ only a limited number $(l)$ of scenarios from among all those possible.

An illustrative example is given in Fig. 1 with $N_{p}=5$, $N_{s}=4$ and $l=10$. In this three-dimensional space, $(x, y, z)$ represents $\left(j, \phi_{\mathbb{\Phi}, i_{j}}(k+j), T_{o ®, i_{j}}(k+j)\right)$. The upper view shows all the $\left(N_{s}^{N_{p}}\right)$ paths associated to all the combinations of $i_{j}$, while the lower view shows some paths judiciously selected according to their energy costs. Each arc extending from one vertex $(x=j-1)$ to another $(x=j)$ is associated with a control scenario $i_{j}$ and its associated energy cost $€_{i_{j}}$. Figures 2 more accurately represent vertices $\left(\phi_{\overparen{D}, i_{j}}(k+j), T_{o \oplus, i_{j}}(k+j)\right)$ (for $\left.j=1, \ldots, 5\right)$ belonging to the cyan transverse planes in Fig. 1.

At each time of prediction $k+j$, blue points of Fig. 2 denote the end-vertices of all the paths generated in a comprehensive manner (related to Fig. 1a). On the other hand, points represented by red circles and red discs in Fig. 2 correspond to the end-vertices of arcs (related to Fig. 1b), which have been generated at the previous time of prediction $k+j-1$ from a set of $l$ "optimal" points $\left(\hat{\phi}_{\mathbb{D}, i_{j-1}}(k+j-1), \hat{T}_{o \mathbb{1}, i_{j-1}}(k+j-1)\right)$. The latter, represented by red discs, are selected owing to their representativeness of the points circled in red (and so of the blue points) and because of the low cost of paths $\left(\phi_{\Phi}(k), T_{o \oplus}(k)\right) \rightarrow\left(\hat{\phi}_{\oplus, i_{j-1}}(k+j-1), \hat{T}_{o \oplus, i_{j-1}}(k+j-1)\right)$ according to criterion $J$.

These $l$ "optimal" points (red discs) are determined at each time of prediction using principal component analysis [14]. The two principal components of the data set containing the coordinates $\left(\hat{\phi}_{\mathbb{\Phi}, i_{j}}(k+j), \hat{T}_{o \mathbb{D}, i_{j}}(k+j)\right)$ of all the points circled in red define two orthogonal directions $\left(V_{1}, V_{2}\right)$, which appear in thick line in Fig. 2. The projection of all the points represented by red circles on $V_{1}$ and $V_{2}$ makes it possible to define a rectangle encompassing all these points. This rectangle is then cut into $l$ small rectangles in which $l$ "optimal" points (represented by red discs) $\left(\hat{\phi}_{\oplus, i_{j-1}}(k+j-1), \hat{T}_{o \oplus, i_{j-1}}(k+j-1)\right)$ are conserved for the next time of prediction.

It has to be mentioned that more the number $l$ is large, more the approximation of the optimal control scenario is good with 

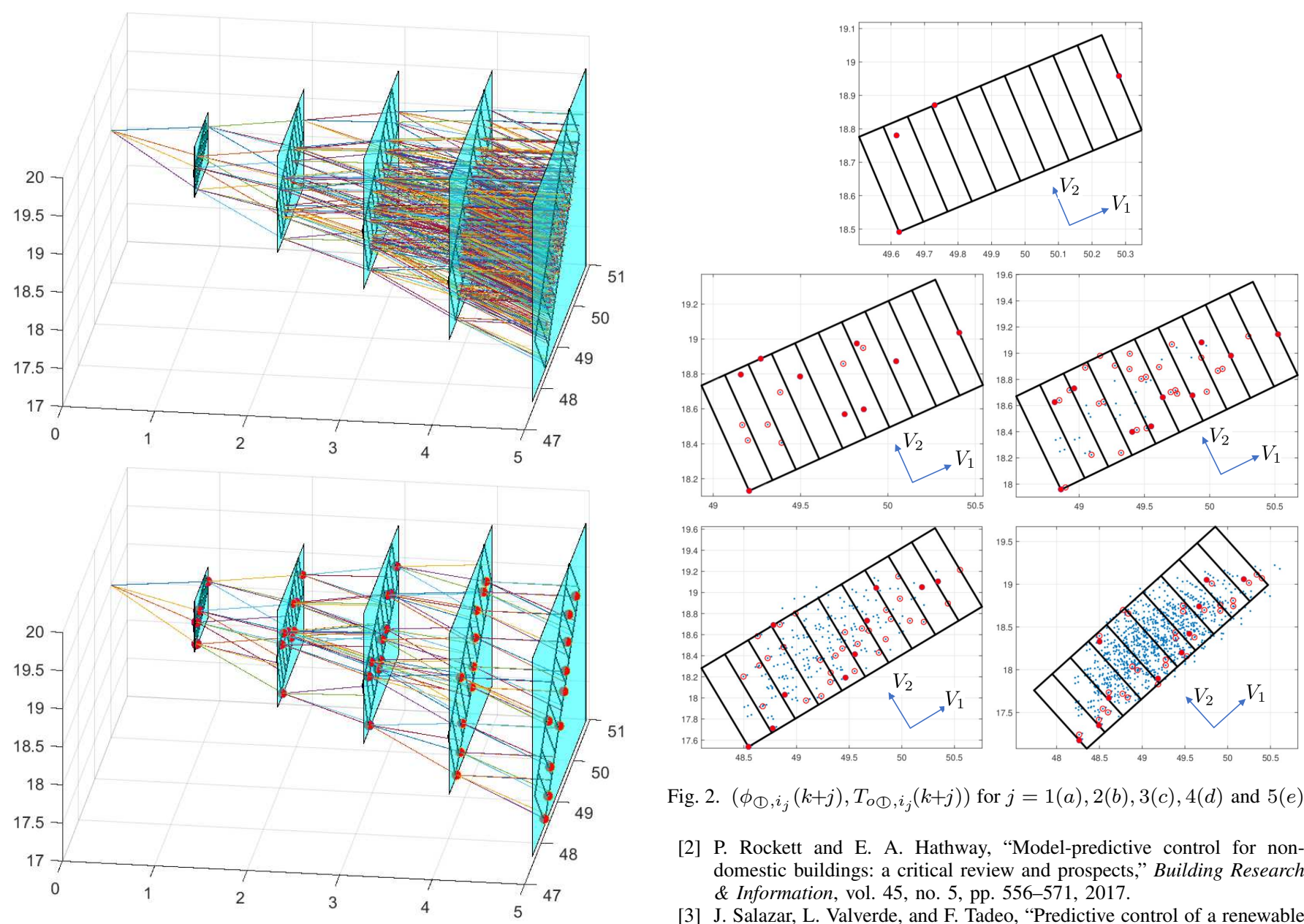

Fig. 2. $\left(\phi_{\mathbb{1}, i_{j}}(k+j), T_{o \oplus, i_{j}}(k+j)\right)$ for $j=1(a), 2(b), 3(c), 4(d)$ and $5(e)$

[2] P. Rockett and E. A. Hathway, "Model-predictive control for nondomestic buildings: a critical review and prospects," Building Research \& Information, vol. 45, no. 5, pp. 556-571, 2017.

[3] J. Salazar, L. Valverde, and F. Tadeo, "Predictive control of a renewable energy microgrid with operational cost optimization," in Proc. IECON 2013 - 39th Annual Conference of the IEEE Industrial Electronics Society, Nov 2013, pp. 7950-7955.

Fig. 1. Prediction of $\left(\phi_{\mathbb{1}, i_{j}}(k+j), T_{o \mathbb{1}, i_{j}}(k+j)\right)$ for $j=1, \ldots, N_{p}$ using a) all the combinations $i_{j} \forall j$, b) the proposed iterative approach.

this iterative approach. On the other hand, the computational load is greatly reduced with proposed iterative approach. Indeed, if the number of arcs is at the maximum equal to $l \cdot N_{s} \cdot N_{p}$ for this algorithm, it can reach $\left(N_{s}^{N_{p}+1}-N_{s}\right) /\left(N_{s}-1\right)$ by an exhaustive search for all possible control scenarios.

\section{CONClusion}

In this paper, a complete methodology has been established for modeling a multi-zone office building and controlling its hygrothermal comfort with the objective of minimizing energy costs. Based on a set of descriptor state-space models and on an energy cost function, an original model predictive control has been designed for considering large prediction horizon without any risk of combinatory explosion. Future research will consist in validating this methodology on a laboratory platform.

\section{REFERENCES}

[1] F. Gabsi, F. Hamelin, R. Pannequin, and M. Chaabane, "Energy efficiency of a multizone office building: MPC-based control and simscape modelling," in Proc. of the 6th International Conference on Smart Cities and Green ICT Systems - Volume 1: SMARTGREENS. Porto, Portugal: INSTICC, April 2017, pp. 227-234.

[4] S. Walker, W. Lombardi, S. Lesecq, and S. Roshany, "Application of distributed model predictive approaches to temperature and co2 concentration control in buildings," in Proc. 20th IFAC World Congress, 7 2017, pp. 2589-2594.

[5] M. Ferroukhi, R. Djedjig, R. Belarbi, K. Limam, and K. Abahri, "Effect of coupled heat, air and moisture transfers modeling in the wall on the hygrothermal behavior of buildings," Energy Procedia, vol. 78, pp. 2584 $-2589,2015$.

[6] F. Gabsi, F. Hamelin, and N. Sauer, "Building hygrothermal modeling by nodal method," in Proc. of the IEEE International Conference on Innovative Smart Grid Technologies (ISGT Asia 2018), Singapore, May 2018.

[7] F. Nicol, "Adaptive thermal comfort standards in the hot-humid tropics." Energy and Buildings, no. 7, p. 628, 2004.

[8] ANSI/ASHRAE Standard 55, Thermal Environmental Conditions for Human Occupancy. Atlanta, Georgia: ASHRAE, 2013.

[9] K. J. McCartney and J. F. Nicol, "Developing an adaptive control algorithm for europe," Energy and Buildings, vol. 34, no. 6, pp. 623 - 635, 2002, special Issue on Thermal Comfort Standards.

[10] T. Ebert, N. Eßig, and G. Hauser, Green Building Certification Systems: Assessing sustainability - International system comparison - Economic impact of certifications, ser. DETAIL Green Books. DETAIL, 2011.

[11] N. Hutcheon and G. Handegord, Building science for a cold climate. Wiley, 1983.

[12] R. L. Webb, "Standard nomenclature for mass transfer processes," International Communications in Heat and Mass Transfer, vol. 17, no. 5, pp. $529-535,1990$.

[13] P. Calow, Blackwell's concise encyclopedia of environmental management. Blackwell Science, 1999.

[14] I. Jolliffe, Principal Component Analysis, ser. Springer Series in Statistics. Springer-Verlag New York, 2002. 